\title{
Improvement for the multi-scale periodic characteristics revealing of precipitation signals and its impact assessment on soil hydrological process by combining HHT and CWT approaches
}

\author{
S. Yu ${ }^{1,2}$, J. Yang ${ }^{1,2}$, G. Liu ${ }^{1}$, R. Yao ${ }^{1,2}$, and X. Wang ${ }^{1}$ \\ ${ }^{1}$ State Key Laboratory of Soil and Sustainable Agriculture, Institute of Soil Science, Chinese Academy of Sciences, \\ 71 East Beijing Road, Nanjing 210008, China \\ ${ }^{2}$ Dongtai Institute of Tidal Flat, Nanjing Branch of the Chinese Academy of Sciences, 8 Beihai Road, Dongtai 224200, China \\ Correspondence to: J. Yang (jsyang@issas.ac.cn)
}

Received: 2 March 2014 - Published in Nat. Hazards Earth Syst. Sci. Discuss.: 6 June 2014

Revised: - - Accepted: 26 January 2015 - Published: 4 March 2015

\begin{abstract}
This study conducts a detailed analysis of multiscale periodic features involved in the annual and seasonal precipitation signals at the typical coastal reclamation region in China by selecting the suitable continuous wavelet transform (CWT) and innovatively combining the improved Hilbert-Huang transform (HHT), and further deduces the precipitation trend and its impacts on the future soil hydrological process. The Morlet wavelet transform is proved suitable in revealing the precipitation signals broad-scale periodicities, however, the critical mode mixing problem in CWT causes the poor significance in the fine-scale periodicities, which cannot well match the climate background. By combining the HHT approach, the fine-scale mode mixing drawback in CWT is effectively eliminated, and the the studied precipitation signals multi-scale periodicities are accurately revealed. Consequently, an overall decreasing trend of annual and seasonal precipitation in future years is demonstrated. Furthermore, by novelly using the cross wavelet transform (XWT) and wavelet transform coherence (WTC) approaches, the prominent correlations between the precipitation dynamics and soil and groundwater salinities dynamics, it is demonstrated that the precipitation increase can effectively leach the surface soil salt downwards into the deeper soil layers and groundwater with 5-7-day lag in the new cultivated tidal land. The revealed future decreasing trend of precipitation, especially in spring and summer, may aggravate the soil salinization at the coastal reclamation region, thus some reasonable salt leaching and evaporation suppression measures
\end{abstract}

need to be taken to prevent the possible soil secondary salinization process.

\section{Introduction}

The precipitation dynamics always plays a prominent role in the soil hydrological process, which impacts significantly on the health of a water-soil-crop system. In particular, at the studied coastal region in northern Jiangsu, China, a huge amount of tidal lands are being enclosed for agricultural utilization, which has aroused international attention, e.g., the planned average annual reclamation amount of about 7000 hectares tidal lands during the year 2010-2020 at Dongtai County takes up about $40 \%$ of the total amounts in China (Wang and Ke, 1997; Meng and Tang, 2010). These new areas commonly need 5-10 years of soil amelioration and desalting before they can be cultivated for wheat and corn in a rain-fed farming system. Thus, the precipitation dynamics at the coastal region play a key role in both the new-land soil desalting process and the cultivated-land soil secondary salinization process (Zhao et al., 2010), that makes the precise study of the precipitation dynamics very important for the agriculture development and environment health in these new areas. However, the uneven precipitation distribution during seasons and years, and the special and stochastic climatic and environmental factors, such as typhoon and storm tide, at the coastal region make the study hard to be precise enough and usually bring some environmental risks, such as the waterlog 
and salinization. In view of this, more effective approaches need to be introduced into the precise analysis of precipitation multi-scale characteristics and the accurate forecast of precipitation trend and its impacts on the soil hydrological process.

Since the hydrometeorological signals are highly nonstationary and their physical processes often operate under a large range of scales varying from 1 day to several decades, the continuous wavelet transform (CWT) has been introduced and developed to reveal the multiple time scales characteristics of these nonstationary signals (Mandelbrot and Wallis, 1968; Grossmann and Morlet, 1984; Mallat, 1989; Daubechies, 1994; Torrence and Compo, 1998; Labat et al., 2000). Because the CWT can provide information about both time and frequency simultaneously, and enables a separation to be made between features associated with different characteristic length scales, it has some advantages over the traditional Fourier transform and has been widely used in revealing the periodic characteristics of hydrometeorological signals at multiple time scales (Walker, 1997; Nener et al., 1999; Coulibaly and Bum, 2004; Labat et al., 2005; Shark and Yu, 2006; Liu et al., 2009; Yu et al., 2013). For hydrometeorological signals, the Morlet and Mexican hat wavelets are two types of the most popularly used continuous wavelets (Foufoula-Georgiou and Kumar, 1995). To well and truly assess the statistical significance of hydrometeorological signals multi-scale periodicities, the wavelet power spectrum and its confidence test are usually requested to be combined with the wavelet transform analysis (Ge, 2007; Zhang et al., 2010). In view of the above background, it is feasible to utilize the CWT approaches to effectively reveal the precipitation's multi-scale characteristics at the studied coastal reclamation region, although little similar research has been carried out at this area.

One major problem in CWT is the frequent appearance of mode mixing (Gong et al., 2005; Huang and Wu, 2008), which is defined as the CWT decomposed information of one scale (or frequency) either consisting of information of other widely disparate scales (or frequencies) or the decomposed information of a similar scale residing in different scales information. Mode mixing is often a consequence of signal intermittency, which may cause serious aliasing in the timefrequency distribution and make the signal's multi-scale periodicities unclear. To overcome the mode mixing problem in CWT, the presented study innovatively introduces the improved Hilbert-Huang transform (HHT) approach, based on the Ensemble Empirical Mode Decomposition (EEMD) algorithm (Wu and Huang, 2009), into the revealing capability improvement of hydrometeorological signals multi-scale periodic characteristics. As a new noise-assisted data analysis method, the EEMD algorithm is proposed based on the original HHT, which is based on the original Empirical Mode Decomposition (EMD) method (Huang et al., 1998, 1999), to overcome the similar mode mixing drawback in EMD as that in CWT. The improved EEMD method defines the true intrinsic mode function (IMF) components as the mean of an ensemble of trials, each consisting of the signal plus a white noise of finite amplitude. Although adding noise may result in smaller signal-to-noise ratio, the added white noise will provide a relatively uniform reference scale distribution to facilitate EMD. Therefore, the low signal-to-noise ratio does not affect the decomposition method but actually enhances it to avoid the mode mixing problems. The HHT is an adaptive time-frequency data analysis method and has been proved quite versatile in a broad range of applications for extracting signals from data generated in noisy nonlinear and nonstationary processes.

One crucial issue in assessing the impact of precipitation dynamics on the future soil hydrological process is to precisely reveal the correlation between the precipitation dynamics and soil and groundwater salinities dynamics. However, the classic regression analysis cannot well reveal the correlation, because the large numbers of zero value data in the daily hydrometeorological signals highly increase the signals noisy and nonlinear dynamics (Yu et al., 2013). Thus, the cross wavelet transform (XWT) and wavelet transform coherence (WTC) approaches are novelly introduced into the study to discuss the resonance feature between the precipitation and salinity signals at multiple time scales. By combining the continuous wavelet analysis and cross spectrum analysis (Roth, 1971; Liu, 1994), the XWT and WTC approaches have been developed and utilized to expose the common power, relative phase and significant coherence of two signals in time-frequency space (Torrence and Webster, 1999; Grinsted et al., 2004). Because of the embedded wavelet theory, the XWT and WTC approaches have advantages over the single cross spectrum analysis in revealing the cross information of nonstationary signals about both time and frequency simultaneously and have been popularly used for meteorological, geophysical, mechanical and electronic signals (Gurley et al., 2003; Jevrejeva et al., 2003; Yang et al., 2009; Yu et al., 2014).

In the remainder of this paper, the studied sites and data details and the methodologies of CWT, XWT, WTC and HHT are presented. In the next section, the results of multi-scale periodic characteristics of different precipitation signals are revealed by selecting the suitable CWT type, and the future precipitation trends at the corresponding dominant scales are deduced and forecasted with the comparison with the traditional linear fitting results. In the discussion section, the mode mixing problems in CWT are discussed by analyzing the climate background of precipitation's multi-scale periodicities and improved by innovatively combining the EEMD based HHT approach. Furthermore, the impacts of the forecasted future precipitation dynamics on the future soil hydrological process are assessed by quantitatively analyzing the correlation between the precipitation and salinization dynamics, where the XWT and WTC approaches are novelly used to reveal the oscillation coherence and time lag property 


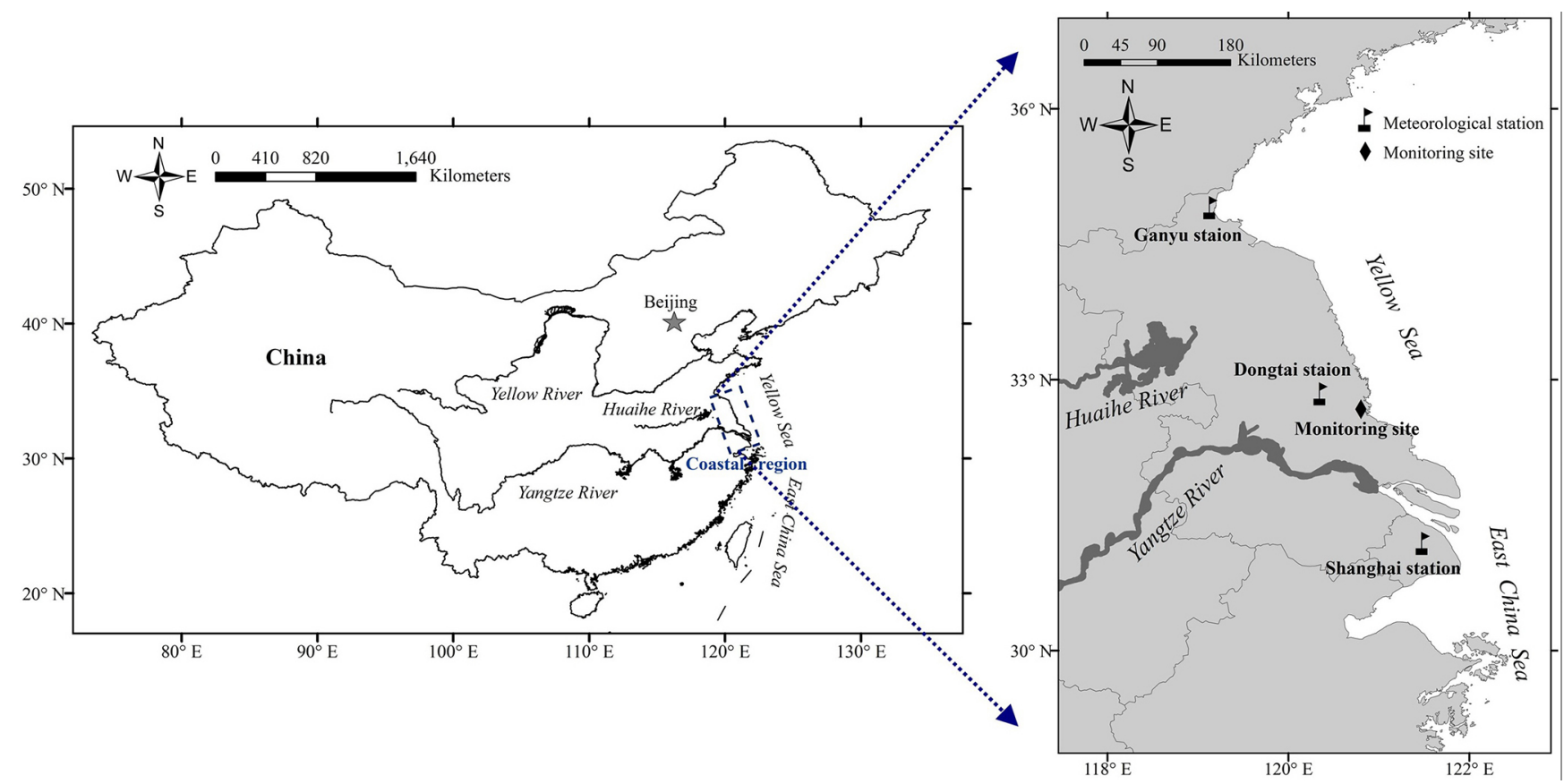

Figure 1. Map showing the locations of the studied meteorological stations and monitoring site.

between the precipitation and groundwater salinity signals at daily scales. Finally, the conclusions are drawn.

\section{Data and methodology}

\subsection{Studied sites and data}

Three meteorological stations in the coastal region of northern Jiangsu, China are selected as the study sites in this paper (Fig. 1). The Ganyu station $\left(34.84^{\circ} \mathrm{N}, 119.12^{\circ} \mathrm{E}\right)$ is located at the north part of Huaihe River valley and is about $5 \mathrm{~km}$ from the Yellow Sea. The Shanghai station $\left(31.16^{\circ} \mathrm{N}\right.$, $121.43^{\circ} \mathrm{E}$ ) is located at the south part of the lower reach of Yangtze River and is about $27 \mathrm{~km}$ from the East China Sea. The Dongtai station $\left(32.85^{\circ} \mathrm{N}, 120.31^{\circ} \mathrm{E}\right)$ is located at the crossing part of the two valleys and is about $54 \mathrm{~km}$ from the Yellow Sea. Supported and quality controlled by China Meteorological Administration, the data of monthly precipitation covering 1957-2011 at the Ganyu station, monthly precipitation covering 1953-2011 at the Dongtai station, and monthly precipitation covering 1951-2011 at the Shanghai station are utilized in this study.

The monitoring site $\left(32.65^{\circ} \mathrm{N}, 120.90^{\circ} \mathrm{E}\right)$ is located at a newly cultivated farmland at the typical reclamation area Dongtai County, which is about $5 \mathrm{~km}$ from the Yellow Sea. This tidal land was enclosed from the sea in 2004 and first cultivated for wheat and corn in June 2011. The soil electrical conductivity (EC) data in the different soil layers (10, 50 and $100 \mathrm{~cm}$ ) were monitored 6 times each month from June 2011 to May 2013. The daily groundwater EC data and the corresponding daily precipitation data covering 1 whole year (365 days) from 11 May 2012 to 10 May 2013 were monitored and collected.

\subsection{Continuous wavelet transform (CWT) and wavelet power spectrum test}

The CWT is a mathematical tool which allows the decomposition of the signal $f(t)$ in terms of elementary contributions called wavelets, which can be thought of as a packet of sine waves of varying amplitude and wavelength (Sadowskey, 1996; Torrence and Compo, 1998; Labat et al., 2000). For time series $f(t) \in L^{2}(R), R$ is the domain of real numbers, or finite energy signal, the CWT of signal $f(t)$ with the analyzing wavelet $\phi$ is the convolution of $f(t)$ with a set of dilated and translated wavelets:

$W_{f}(a, b)=\left\langle f(t), \varphi_{a, b}(t)\right\rangle=\sqrt{\frac{\delta t}{a}} \int_{R} f(t) \bar{\varphi}\left(\frac{t-b}{a}\right) \mathrm{d} t$,

where $a$ is the dilation (scale or frequency) parameter, $b$ is the translation (position or time) parameter, $\bar{\phi}(t)$ is the complex conjugate functions of $\phi(t)$, and $\delta t$ is the time interval of data series. In this study, two popularly used wavelets, the Mexican hat and Morlet wavelets (Eq. 2), were selected as the $\phi$ (Mallat, 1989; Daubechies, 1994; Torrence and Compo, 1998). The Mexican hat wavelet, as a real-value wavelet function, is the second derivative of the Gaussian function. The Morlet wavelet, as a complex wavelet, consists of a plane wave modulated by a Gaussian function: 
(Mexicanhat) $\phi(t)=\left(\frac{2}{\sqrt{3}} \pi^{-1 / 4}\right)\left(1-t^{2}\right) e^{\left(-t^{2} / 2\right)}$,

(Morlet) $\phi(t)=\pi^{-1 / 4} e^{i \omega_{0} t} e^{\left(-t^{2} / 2\right)}$,

where $\omega_{0}$ is the non-dimensional frequency, usually taken to be 6 to satisfy the admissibility condition (Farge, 1992; Torrence and Compo, 1998).

The global wavelet power spectrum is defined as $E_{a}=$ $\frac{1}{N} \sum_{b=1}^{N}\left|W_{f}(a, b)\right|^{2}$, where $N$ is the length of data. The statistical significance of wavelet power can be assessed relative to the null hypotheses that the signal is generated by a stationary process with a given background power spectrum $(P)$ (Torrence and Compo, 1998). For the global wavelet power spectrum test, the theoretical spectrum $P$ is defined as $P=\sigma^{2} P_{k} x_{v}^{2} / v$, where $\sigma^{2}$ is the variance of data series, $x_{v}^{2}$ is the chi square when degrees of freedom is $v$ at the requested confidence level, and $P_{k}$ is the Fourier white noise or red noise power spectrum. $P_{k}$ is defined as Eq. (3)

$P_{k}=\frac{1-r(1)^{2}}{1+r(1)^{2}-2 \cdot r(1) \cdot \cos \left(2 \pi \delta_{t} / T\right)}$,

where $r(1)$ is the autocorrelation coefficient under a first order lag of data series, and $T$ is the period of data series. Theoretically, for Morlet wavelet, $T \approx 1.033 a$, while for Mexican hat wavelet, $T \approx 3.974 a$ (Torrence and Compo 1998). When $r(1)>0.1, P_{k}$ is red noise spectrum, and when $r(1) \leq 0.1, P_{k}$ is white noise spectrum and equals the default value 1.0 (Allen and Smith, 1996; Ge, 2007). The $v$ values in Mexican hat and Morlet wavelet power spectrums are calculated by

(Mexicanhat) $v=\sqrt{1+\left(\frac{N \delta t}{1.43 a}\right)^{2}}$

(Morlet) $v=2 \sqrt{1+\left(\frac{N \delta t}{2.32 a}\right)^{2}}$.

\subsection{Cross wavelet transform (XWT) and wavelet transform coherence (WTC)}

The XWT of two signals $x(t)$ and $y(t)$ with finite energy is defined as $W_{x y}(a, b)=W_{x}(a, b) W_{y}^{*}(a, b)$, where * denotes complex conjugation. The cross wavelet power spectrum is defined as $\left|W_{x y}(a, b)\right|^{2}=\left|W_{x y}(a, b) W_{x y}^{*}(a, b)\right|$. The theoretical distribution of the cross wavelet power of two signals with background power spectrum $P_{k}^{x}$ and $P_{k}^{y}$ is given by Torrence and Compo (1998) as

$$
D\left(\frac{\left|W_{x y}(a, b)\right|^{2}}{\sigma_{x} \sigma_{y}}<p\right)=\frac{Z_{v}(p)}{v} \sqrt{P_{k}^{x} P_{k}^{y}},
$$

where $Z_{v}(p)$ is the confidence level associated with the probability $p$ for a probability density function (PDF) defined by the square root of the product of two chi-square distributions. In this study 0.05 significance level was selected and $Z_{2}(95 \%)=3.999$ (Grinsted et al., 2004).

Because the wavelet is not completely localized in time, the XWT has edge artifacts and a cone of influence (COI) in which edge effects cannot be ignored is introduced. Here the COI is taken as the area in which the wavelet power caused by a discontinuity at the edge has dropped to $\mathrm{e}^{-2}$ of the value at the edge (Grinsted et al., 2004). The phase difference between the components of two signals, revealed from the complex angles of $W_{x y}(a, b)$, can be estimated by calculating the mean and confidence interval of the phase difference. The circular mean of the phase over regions with higher than $5 \%$ statistical significance that are outside the COI are used to quantify the phase relationship. The circular mean of a set of angles $\left(\alpha_{i}, i=1 \ldots n\right)$ is defined as (Zar, 1999)

$\bar{\alpha}_{i}=\arg (X, Y) ; \quad X=\sum_{i=1}^{n} \cos \left(\alpha_{i}\right) ; \quad Y=\sum_{i=1}^{n} \sin \left(\alpha_{i}\right)$.

The circular standard deviation, reflecting the scatter of angles around the mean, is defined as $s=\sqrt{-2 \operatorname{In}(R / n)}$, where $R=\sqrt{X^{2}+Y^{2}}$. The circular standard deviation is analogous to the linear standard deviation, in that it varies from zero to infinity. In some cases there might be reasons for calculating the mean phase angle for each scale, and then the phase angle can be quantified as a number of days.

Analysis of the wavelet transform coherence (WTC) of two signals $x(t)$ and $y(t)$ is another useful measure to reveal the high common wavelet power and the localized correlation coefficient of the two signals in time frequency space. The wavelet coherence is defined by Torrence and Webster (1999) as

$$
R^{2}(a, b)=\frac{\left|S\left(a^{-1} W_{x y}(a, b)\right)\right|^{2}}{S\left(a^{-1}\left|W_{x}(a, b)\right|^{2}\right) \cdot S\left(a^{-1}\left|W_{y}(a, b)\right|^{2}\right)},
$$

where $S$ is a smoothing operator. For the Morlet wavelet a suitable smoothing operator is given by Torrence and Webster (1999):

$$
\begin{aligned}
& \left.S_{\text {time }}\left(W_{f}(a, b)\right)\right|_{a}=\left.\left(W_{f}(a, b) \cdot c_{1}^{-t^{2} /\left(2 a^{2}\right)}\right)\right|_{q}, \\
& \left.S_{\text {scale }}\left(W_{f}(a, b)\right)\right|_{t}=\left.\left(W_{f}(a, b) \cdot c_{2} \prod(0.6 a)\right)\right|_{t},
\end{aligned}
$$

where $S_{\text {scale }}$ denotes smoothing along the wavelet scale axis, $S_{\text {time }}$ denotes smoothing in time, $c_{1}$ and $c_{2}$ are normalization constants and $\prod$ is the rectangle function. The statistical significance level of WTC is estimated using Monte Carlo methods (Grinsted et al., 2004).

\subsection{Hilbert-Huang transform (HHT)}

In the original HHT, based on the Empirical Mode Decomposition (EMD) approach, the data series $x(t)$ is decomposed 

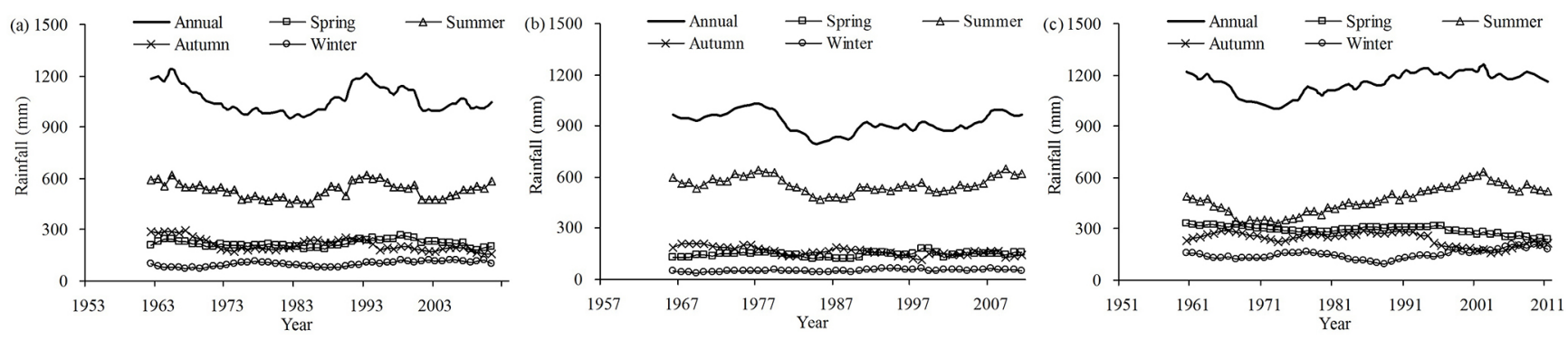

Figure 2. 10-year running means of the annual and seasonal precipitation signals at Ganyu during 1957-2011 (a), Dongtai during 19532011 (b) and Shanghai during 1951-2011 (c).

in terms of truth, intrinsic mode functions (IMFs), and trend $(R)$ components (Huang et al., 1998, 1999):

$x(t)=\sum_{j=1}^{n} c_{j}+R_{n}$

where $c_{j}$ is the IMF component, and $R_{n}$ is the residue of data $x(t)$ after $n$ number of IMFs are extracted.

As proposed by Wu and Huang (2009), the first step of Ensemble Empirical Mode Decomposition (EEMD) process is to add a white noise series $w(t)$ to the targeted data. The added white noise is treated as the possible random noise that would be encountered in the measurement process. Under such conditions, the $i$ th "artificial" observation will be

$x_{i}(t)=x(t)+w_{i}(t)$.

In the case of only one observation, each multipleobservation ensemble is mimicked by adding not arbitrary but different realizations of white noise $\left(w_{i}(t)\right)$ to that single observation as given in Eq. (11). The second step is to decompose the data with added white noise into IMFs. Repeat step 1 and step 2 again and again, but with different white noise series each time, and at last obtain the ensemble means of corresponding IMFs of the decompositions as the final result. As the ensemble number approaches infinity, the truth, $c_{j}(t)$, as defined by EEMD, is

$c_{j}(t)=\lim _{N \rightarrow \infty} \frac{1}{N} \sum_{k=1}^{N}\left[c_{j k}(t)\right]$,

$c_{j k}(t)=c_{j}(t)+R_{j k}(t)$,

where $R_{j k}(t)$ is the contribution to the $j$ th IMF from the added white noise of the $k$ th trial of the $j$ th IMF in the noiseadded signal. The amplitude of noise $w_{i}(t)$ is not necessarily small, usually setting an amplitude of 0.2 of that of the standard deviation of the corresponding data. But the ensemble number of the trials $N$ has to be large, usually not lower than 100.
The HHT marginal spectrum represents the accumulated amplitude (energy) over the entire data span in a probabilistic sense and offers a measure of the total amplitude (energy) contribution from each frequency (period) value, serving as an alternative spectrum expression of the traditional Fourier spectrum. The marginal spectrum is defined as (Huang and $\mathrm{Wu}, 2008)$

$h(\omega)=\int_{0}^{T} H(\omega, t) \mathrm{d} t$,

where $[0, T]$ is the temporal domain within which the data is defined, $H$ expresses the amplitude in terms of a function of time and frequency, and $\omega$ is the instantaneous frequency. All the CWT, XWT, WTC and HHT in this paper were carried out in MATLAB.

\section{Results}

\subsection{Precipitation trend forecast based on the conventional linear fitting method}

The average coefficients of variation for the monthly precipitation during each year reached 122.1, 95.4 and $75.6 \%$ at the coastal Ganyu, Dongtai and Shanghai meteorological stations, respectively, and for the annual precipitation among years reached $24.5,24.0$ and $18.4 \%$, respectively. The prominent uneven precipitation distribution during seasons and years in the studied area and a slightly decreasing trend of this kind of unevenness with the latitude dropping were revealed. The summer precipitation made up 61.0, 51.0 and $41.4 \%$ of the annual precipitation at Ganyu, Dongtai and Shanghai, respectively, with the significant correlation coefficients of $0.88,0.84$ and 0.77 , respectively, between the summer and annual precipitation at the 0.05 confidence levels. Further more, the 10-year running means of summer precipitation signals showed the most similar dynamic curves with the annual precipitation signals (Fig. 2). The above analysis indicated that the summer precipitation dynamics played a dominant role in the annual precipitation changes in the studied area. 
Table 1. Fitting equations of the annual and seasonal precipitation series at the Ganyu, Dongtai and Shanghai stations based on the original data and 10-year running means data ( $y$ denotes the annual or seasonal precipitation $(\mathrm{mm}), x$ denotes the time series $(1,2,3, \ldots), r$ and $P$ denote the correlation coefficient and $P$ value in the regression model.

\begin{tabular}{|c|c|c|c|c|c|c|}
\hline \multirow[b]{2}{*}{$\begin{array}{l}\text { Precipitation } \\
\text { signals }\end{array}$} & \multicolumn{2}{|c|}{ Fitting equations at Ganyu } & \multicolumn{2}{|c|}{ Fitting equations at Dongtai } & \multicolumn{2}{|c|}{ Fitting equations at Shanghai } \\
\hline & $\begin{array}{l}\text { Based on } \\
\text { original data }\end{array}$ & $\begin{array}{l}\text { Based on 10-year } \\
\text { running means data }\end{array}$ & $\begin{array}{l}\text { Based on } \\
\text { original data }\end{array}$ & $\begin{array}{l}\text { Based on 10-year } \\
\text { running means data }\end{array}$ & $\begin{array}{l}\text { Based on } \\
\text { original data }\end{array}$ & $\begin{array}{l}\text { Based on 10-year } \\
\text { running means data }\end{array}$ \\
\hline $\begin{array}{l}\text { Annual } \\
\text { precipitation }\end{array}$ & $\begin{array}{l}y=-0.883 x+954.7 \\
r=0.06, P=0.65\end{array}$ & $\begin{array}{l}y=-0.860 x+948.8 \\
r=0.19, P=0.21\end{array}$ & $\begin{array}{l}y=- \\
1.321 x+1107.4 \\
r=0.09, P=0.50\end{array}$ & $\begin{array}{l}y=-1.096 x+1089.9 \\
r=0.21, P=0.15\end{array}$ & $\begin{array}{l}y=1.288 x+1119.9 \\
\mathrm{r}=0.11, P=0.41\end{array}$ & $\begin{array}{l}y=2.497 x+1064.5 \\
r=0.55, \\
P=2.08 \times 10^{-5}\end{array}$ \\
\hline $\begin{array}{l}\text { Spring } \\
\text { precipitation }\end{array}$ & $\begin{array}{l}y=0.397 x+133.4 \\
r=0.09, P=0.49\end{array}$ & $\begin{array}{l}y=0.317 x+135.8 \\
r=0.31, P=0.03\end{array}$ & $\begin{array}{l}y=-0.126 x+219.6 \\
r=0.03, P=0.84\end{array}$ & $\begin{array}{l}y=0.099 x+216.3 \\
r=0.07, P=0.63\end{array}$ & $\begin{array}{l}y=-1.406 x+332.6 \\
r=0.31, P=0.02\end{array}$ & $\begin{array}{l}y=-1.164 x+334.9 \\
r=0.74, \\
P=4.43 \times 10^{-10}\end{array}$ \\
\hline $\begin{array}{l}\text { Summer } \\
\text { precipitation }\end{array}$ & $\begin{array}{l}y=-0.229 x+573.4 \\
r=0.02, P=0.88\end{array}$ & $\begin{array}{l}y=-0.234 x+565.1 \\
r=0.07, P=0.66\end{array}$ & $\begin{array}{l}y=0.025 x+543.3 \\
r=0.002, P=0.99\end{array}$ & $\begin{array}{l}y=-0.277 x+538.2 \\
r=0.09, P=0.55\end{array}$ & $\begin{array}{l}y=3.167 x+382.4 \\
r=0.31, P=0.01\end{array}$ & $\begin{array}{l}y=4.213 x+319.2 \\
r=0.77 \\
P=2.51 \times 10^{-11}\end{array}$ \\
\hline $\begin{array}{l}\text { Autumn } \\
\text { precipitation }\end{array}$ & $\begin{array}{l}y=-1.233 x+200.4 \\
r=0.20, P=0.14\end{array}$ & $\begin{array}{l}y=-1.308 x+207.6 \\
r=0.71 \\
P=2.82 \times 10^{-8}\end{array}$ & $\begin{array}{l}y=-1.523 x+253.3 \\
r=0.24, P=0.06\end{array}$ & $\begin{array}{l}y=-1.641 x+254.8 \\
r=0.64 \\
P=6.70 \times 10^{-7}\end{array}$ & $\begin{array}{l}y=-1.056 x+270.4 \\
r=0.19, P=0.15\end{array}$ & $\begin{array}{l}y=-1.564 x+296.7 \\
r=0.63 \\
P=7.26 \times 10^{-7}\end{array}$ \\
\hline $\begin{array}{l}\text { Winter } \\
\text { precipitation }\end{array}$ & $\begin{array}{l}y=0.183 x+47.4 \\
r=0.11, P=0.45\end{array}$ & $\begin{array}{l}y=0.365 x+40.3 \\
r=0.70, P=5.20 \times 10^{-8}\end{array}$ & $\begin{array}{l}y=0.303 x+91.2 \\
r=0.12, P=0.38\end{array}$ & $\begin{array}{l}y=0.723 x+80.5 \\
r=0.68 \\
P=4.36 \times 10^{-8}\end{array}$ & $\begin{array}{l}y=0.583 x+134.5 \\
r=0.17, P=0.20\end{array}$ & $\begin{array}{l}y=1.012 x+113.7 \\
r=0.55 \\
P=2.57 \times 10^{-5}\end{array}$ \\
\hline
\end{tabular}

As one conventional method for assessing the precipitation dynamics, the original precipitation data series are usually treated by linear fitting, in which the 10 times of the slope of fitting line, i.e., the climate tendency rate, denotes the precipitation changes of every 10 years (Xu et al., 2004; Wang et al., 2006). A negative climate tendency rate denotes a decreasing precipitation trend, while a positive one denotes an increasing trend. The fitting equations for the original annual and seasonal precipitation data series, together with the fitting equations for the 10-year running means data, at the three studied stations were computed and shown in Table 1. Results showed that the climate tendency rates of annual precipitation at Ganyu, Dongtai and Shanghai were -8.83 , -13.21 and $12.88 \mathrm{~mm} / 10$ years, respectively, which indicated the decreasing trends of annual precipitation at Ganyu and Dongtai and the increasing trend at Shanghai. The climate tendency rates of seasonal precipitation at different meteorological stations were calculated in the same way. However, it should be noted that most of the fitting equations based on the original precipitation data did not pass the statistical test at 0.05 confidence level. Although the statistic significance of fitting equations based on the 10-year running means data increased slightly, the overall performance of precipitation trend forecast based on the conventional analysis was too poor to be used for the accurate precipitation dynamics assessment. In view of this, the popular wavelet analysis method continuous wavelet transform (CWT) was introduced into the precipitation trend forecast by revealing the periodic characteristics of precipitation signals at multiple temporal-frequency scales.
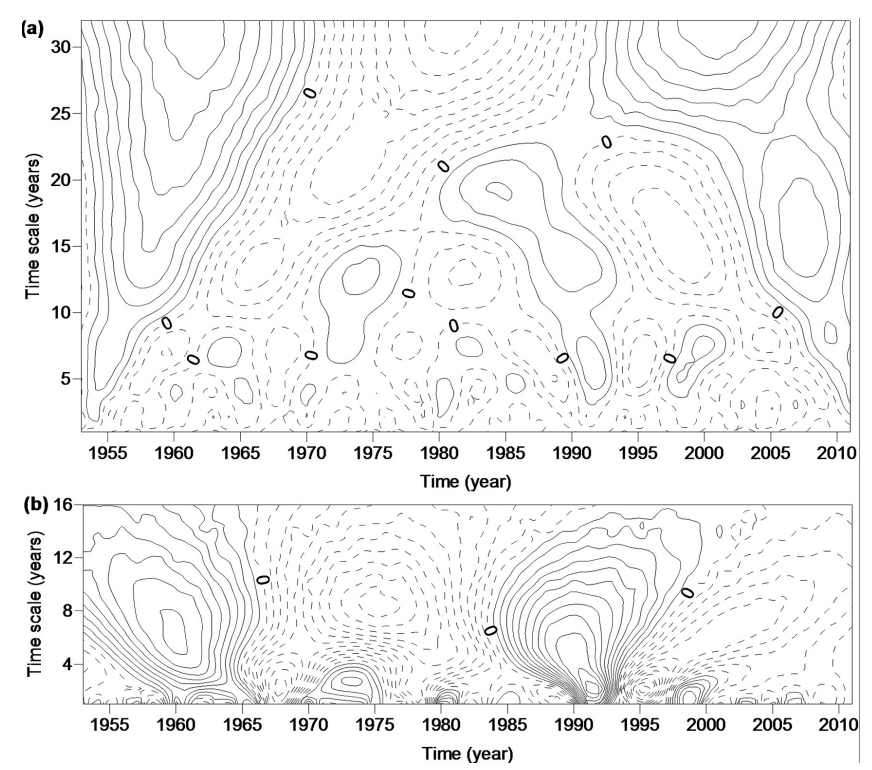

Figure 3. Real parts of the Morlet (a) and Mexican hat (b) wavelet transform coefficients of the annual precipitation at Dongtai during 1953-2011.

\subsection{Multi-scale periodic characteristics of annual and seasonal precipitation signals based on CWT}

The Morlet and Mexican hat wavelet transform coefficients of annual and seasonal precipitation signals at different meteorological stations were calculated by MATLAB. Taking the annual precipitation at Dongtai as an example (Fig. 3), the Morlet and Mexican hat wavelet transform coefficients clearly indicated the distribution of the annual precipitation signal at multiple time scales. The solid isograms indicated 

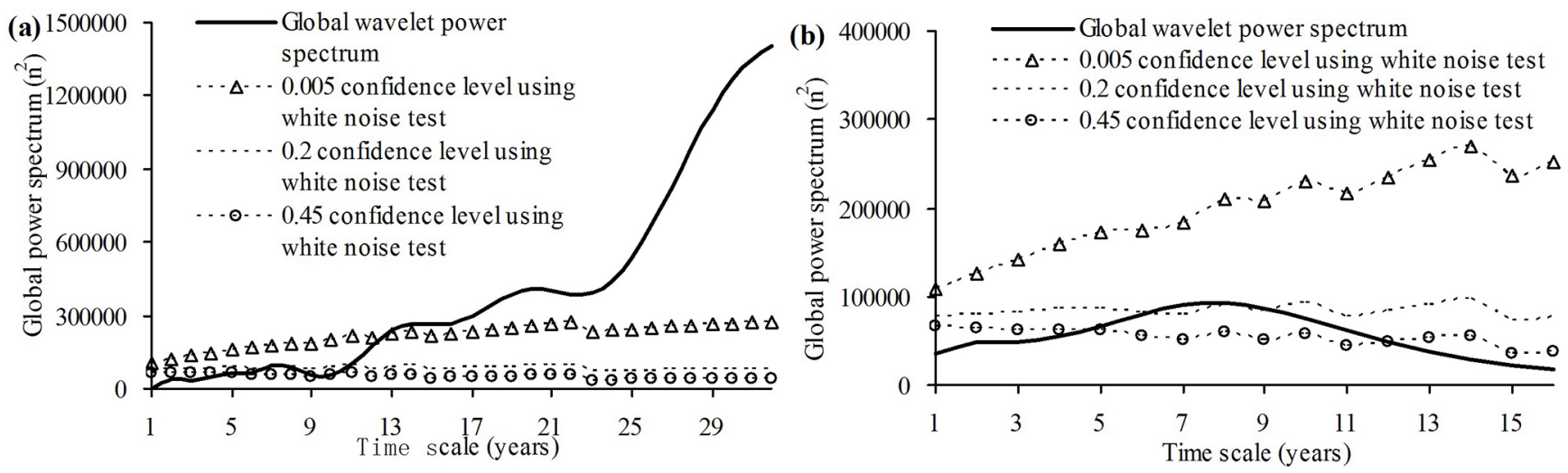

Figure 4. Global wavelet power spectra and their confidence tests using the white noise model for the Morlet (a) and Mexican hat (b) wavelet transforms of the annual precipitation at Dongtai during 1953-2011.

the positive wavelet coefficients and an increasing trend of the annual precipitation, and the dashed isograms indicated the negative wavelet coefficients and a decreasing trend. In order to more directly reveal the precipitation signal's multiscale periodic characteristics, the global wavelet power spectra based on the Morlet and Mexican hat wavelet transform coefficients were calculated and shown in Fig. 4. Since the $r(1)$ of Dongtai annual precipitation data series was -0.23 , the corresponding theoretical power spectra for testing the Morlet and Mexican hat wavelet power density significances at different time scales were calculated by using the white noise model.

Results showed that the Morlet wavelet transform coefficients of Dongtai annual precipitation signal generated five kinds of quasi periodic oscillations (QPOs), namely at 20, 14-, 7-, 5- and 2-year time scales (Figs. 3a and 4a). The corresponding average changing periodicities $(T)$ of Dongtai annual precipitation signal (i.e., the average cycle years between each two time domains with positive wavelet coefficients) at the five time scales were 24, 16, 9, 5 and 2 years, respectively, which were obtained by calculating and averaging the year numbers of each two neighboring high and low precipitation periods. Among the five QPOs, the 24- and 16year periods passed the 0.005 confidence test, and the 9 -year period passed the 0.2 confidence test, but the 5- and 2-year periods showed very poor significances. With respect to the Mexican hat wavelet transform, only one QPO at an 8-year time scale was revealed and its corresponding period $T$ was 31 years, which passed the 0.2 confidence test. The multiscale periodic characteristics for the Dongtai seasonal precipitation signals and for the annual and seasonal precipitation signals at the Ganyu and Shanghai stations based on the Morlet and Mexican hat wavelet transforms were obtained in the same way, and were shown in Tables 2-4. It should be noted that the global wavelet power spectra of the Shanghai autumn and winter precipitation series were tested using the red noise model because their $r(1)$ were 0.13 and 0.16 , respectively.
Comparing the two types of CWTs performances, the Morlet wavelet transform showed more significant advantage than the Mexican hat in capturing the oscillatory behaviors and revealing the local features of the studied precipitation signals periodicities, especially prominent in increasing the confidence level of the wavelet power spectrum test. In view of this, the dominant precipitation periods with the highest confidence level revealed from the Morlet wavelet transform were selected to further deduce and forecast the annual and seasonal precipitation trends in the studied area.

\subsection{Precipitation trend forecast based on CWT}

According to the dominant periods of annual and seasonal precipitation signals revealed by the Morlet wavelet transforms, the precipitation trends in future years were forecasted by deducing the future fluctuating of the wavelet transform coefficient curves at the corresponding dominant time scales. Taking the Dongtai precipitation forecast as an example, two dominant periods of 24 and 16 years, both of which passed 0.005 significance tests, were revealed in both the annual and summer precipitation signals, and the dominant periods of 16, 23 and 17 years were revealed in the spring, autumn and winter precipitation signals, respectively. The corresponding wavelet coefficient curves for the annual and seasonal precipitation at different dominant time scales were shown in Fig. 5. Each single cycle in the wavelet coefficient curve was constituted by a high-precipitation half-period, in which the wavelet coefficients were positive, and a low-precipitation half-period, in which the coefficients were negative. Results in Fig. 5 showed that all the wavelet coefficients of annual and seasonal precipitation in 2011 located at the end of each high-precipitation half-period, which indicated that the annual and summer precipitation in the next 8-12 years, the spring precipitation in the next 8 years, the autumn precipitation in the next 12 years, and the winter precipitation in the next 8 years would probably be in the relatively low periods. 
Table 2. Annual and seasonal precipitation periods and their significances at different time scales based on the Morlet and Mexican hat wavelet transforms at the Ganyu station.

\begin{tabular}{cccccccc}
\hline & & \multicolumn{3}{c}{ Morlet wavelet } & \multicolumn{2}{c}{ Mexican hat wavelet } \\
\cline { 3 - 7 } $\begin{array}{c}\text { Precipitation } \\
\text { signals }\end{array}$ & $\begin{array}{c}\text { Periodicity } \\
\text { levels }\end{array}$ & $\begin{array}{c}a \\
\text { (years) }\end{array}$ & $\begin{array}{c}T \\
\text { (years) }\end{array}$ & $\begin{array}{c}\text { Confidence } \\
\text { level }\end{array}$ & $\begin{array}{c}a \\
\text { (years) }\end{array}$ & $\begin{array}{c}T \\
\text { (years) }\end{array}$ & $\begin{array}{c}\text { Confidence } \\
\text { level }\end{array}$ \\
\hline Annual & First & 11 & 17 & 0.001 & 3 & 15 & 0.10 \\
precipitation & Second & 18 & 21 & 0.01 & - & - & - \\
& Third & 4 & 5 & 0.25 & - & - & - \\
\hline Spring & First & 5 & 6 & 0.05 & 2 & 8 & 0.15 \\
precipitation & Second & 13 & 16 & 0.30 & - & - & - \\
\hline \multirow{2}{*}{ Summer } & First & 13 & 15 & 0.005 & 3 & 11 & 0.15 \\
precipitation & Second & 18 & 21 & 0.10 & - & - & - \\
& Third & 4 & 5 & 0.30 & - & - & - \\
\hline Autumn & Fourth & 2 & 3 & 0.95 & - & - & - \\
precipitation & First & 10 & 12 & 0.05 & 3 & 12 & 0.05 \\
\hline Winter & Second & 18 & 21 & 0.15 & - & - & - \\
precipitation & First & 13 & 16 & 0.20 & 3 & 15 & 0.40 \\
& Second & 8 & 11 & 0.40 & - & - & - \\
\hline & Third & 3 & 4 & 0.75 & - & - & - \\
\hline
\end{tabular}

Table 3. Annual and seasonal precipitation periods and their significances at different time scales based on the Morlet and Mexican hat wavelet transforms at the Dongtai station.

\begin{tabular}{cccccccc}
\hline & & \multicolumn{3}{c}{ Morlet wavelet } & \multicolumn{2}{c}{ Mexican hat wavelet } \\
\cline { 3 - 7 } $\begin{array}{c}\text { Precipitation } \\
\text { signals }\end{array}$ & $\begin{array}{c}\text { Periodicity } \\
\text { levels }\end{array}$ & $\begin{array}{c}a \\
\text { (years) }\end{array}$ & $\begin{array}{c}T \\
\text { (years) }\end{array}$ & $\begin{array}{c}\text { Confidence } \\
\text { level }\end{array}$ & $\begin{array}{c}a \\
\text { (years) }\end{array}$ & $\begin{array}{c}T \\
\text { (years) }\end{array}$ & $\begin{array}{c}\text { Confidence } \\
\text { level }\end{array}$ \\
\hline \multirow{4}{*}{ Annual } & First & 20 & 24 & 0.005 & 8 & 31 & 0.20 \\
precipitation & Second & 14 & 16 & 0.005 & - & - & - \\
& Third & 7 & 9 & 0.20 & - & - & - \\
& Fourth & 5 & 5 & 0.45 & - & - & - \\
Spring & Fifth & 2 & 2 & 0.91 & - & - & - \\
precipitation & First & 14 & 16 & 0.15 & 8 & 33 & 0.45 \\
& Second & 3 & 4 & 0.45 & 1 & 4 & 0.60 \\
& Third & 8 & 11 & 0.40 & - & - & - \\
\hline \multirow{2}{*}{ Summer } & First & 20 & 24 & 0.05 & 6 & 25 & 0.55 \\
precipitation & Second & 15 & 16 & 0.05 & 1 & 4 & 0.96 \\
& Third & 7 & 9 & 0.25 & - & - & - \\
& Fourth & 4 & 5 & 0.55 & - & - & - \\
\hline Autumn & Fifth & 2 & 3 & 0.90 & - & - & - \\
precipitation & First & 19 & 23 & 0.10 & 6 & 25 & 0.15 \\
& Second & 6 & 7 & 0.40 & - & - & - \\
\hline Winter & Third & 4 & 5 & 0.65 & - & - & - \\
\hline precipitation & First & 14 & 17 & 0.05 & 5 & 23 & 0.15 \\
& Second & 4 & 5 & 0.35 & 1 & 5 & 0.80 \\
& Third & 7 & 9 & 0.50 & - & - & - \\
\hline
\end{tabular}


Table 4. Annual and seasonal precipitation periods and their significances at different time scales based on the Morlet and Mexican hat wavelet transforms at the Shanghai station.

\begin{tabular}{|c|c|c|c|c|c|c|c|}
\hline \multirow[b]{2}{*}{$\begin{array}{l}\text { Precipitation } \\
\text { signals }\end{array}$} & \multirow[b]{2}{*}{$\begin{array}{l}\text { Periodicity } \\
\text { levels }\end{array}$} & \multicolumn{3}{|c|}{ Morlet wavelet } & \multicolumn{3}{|c|}{ Mexican hat wavelet } \\
\hline & & $\begin{array}{c}a \\
\text { (years) }\end{array}$ & $\begin{array}{c}T \\
\text { (years) }\end{array}$ & $\begin{array}{c}\text { Confidence } \\
\text { level }\end{array}$ & $\begin{array}{c}a \\
\text { (years) }\end{array}$ & $\begin{array}{c}T \\
\text { (years) }\end{array}$ & $\begin{array}{c}\text { Confidence } \\
\text { level }\end{array}$ \\
\hline \multirow{4}{*}{$\begin{array}{c}\text { Annual } \\
\text { precipitation }\end{array}$} & First & 20 & 24 & 0.001 & 2 & 7 & 0.80 \\
\hline & Second & 9 & 11 & 0.05 & - & - & - \\
\hline & Third & 4 & 5 & 0.70 & - & - & - \\
\hline & Fourth & 2 & 3 & 0.75 & - & - & - \\
\hline \multirow{3}{*}{$\begin{array}{l}\text { Spring } \\
\text { precipitation }\end{array}$} & First & 21 & 24 & 0.01 & 9 & 30 & 0.20 \\
\hline & Second & 3 & 4 & 0.40 & 3 & 11 & 0.80 \\
\hline & Third & 7 & 8 & 0.40 & - & - & - \\
\hline \multirow{3}{*}{$\begin{array}{c}\text { Summer } \\
\text { precipitation }\end{array}$} & First & 20 & 24 & 0.05 & 3 & 14 & 0.55 \\
\hline & Second & 9 & 11 & 0.10 & - & - & - \\
\hline & Third & 3 & 3 & 0.95 & - & - & - \\
\hline \multirow{3}{*}{$\begin{array}{c}\text { Autumn } \\
\text { precipitation }\end{array}$} & First & 20 & 25 & 0.05 & 3 & 11 & 0.20 \\
\hline & Second & 9 & 11 & 0.20 & - & - & - \\
\hline & Third & 4 & 5 & 0.75 & - & - & - \\
\hline \multirow{3}{*}{$\begin{array}{c}\text { Winter } \\
\text { precipitation }\end{array}$} & First & 14 & 17 & 0.05 & - & - & - \\
\hline & Second & 3 & 4 & 0.35 & - & - & - \\
\hline & Third & 6 & 8 & 0.60 & - & - & - \\
\hline
\end{tabular}
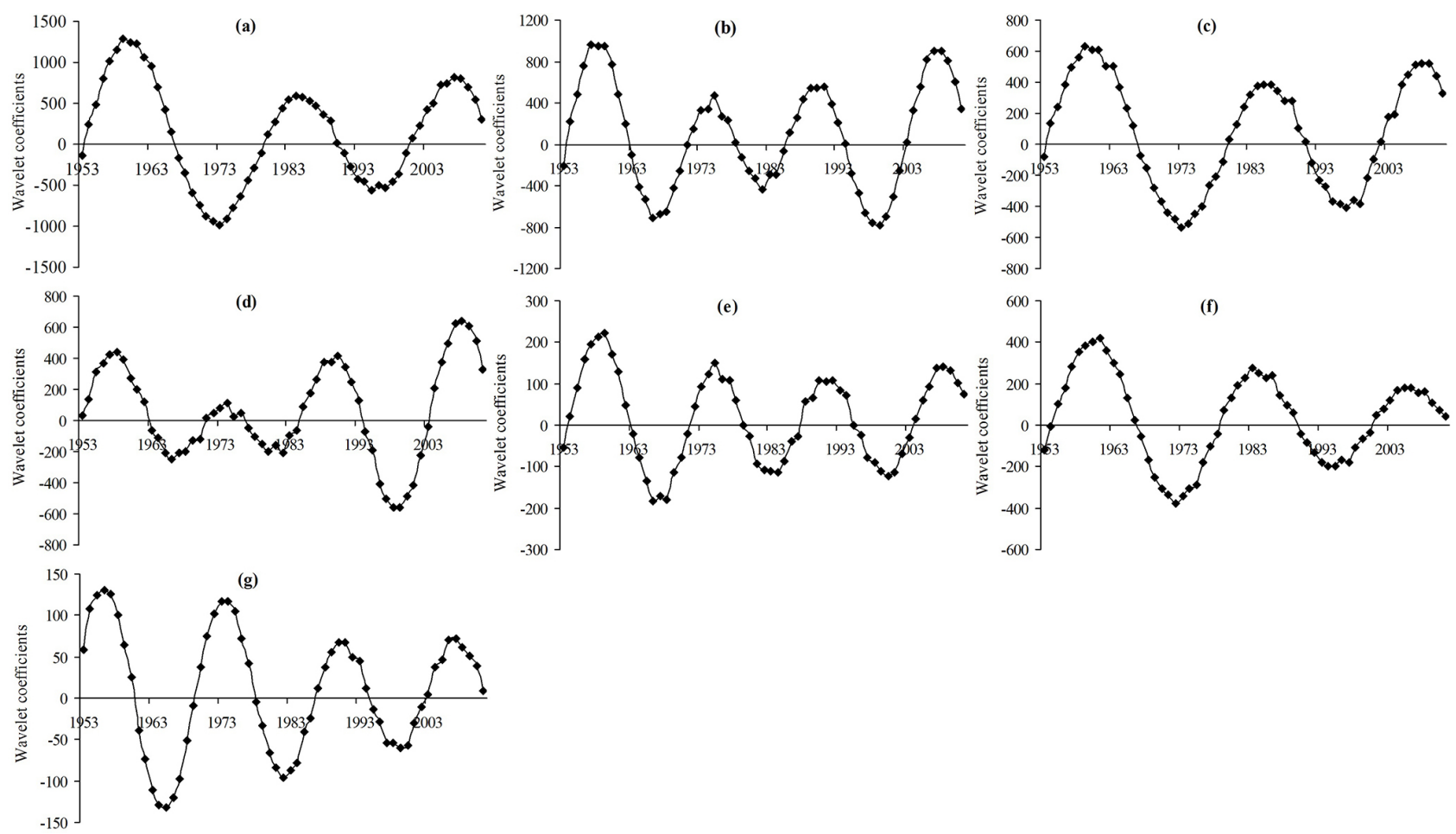

Figure 5. Morlet wavelet transform coefficients for the Dongtai annual and summer precipitation signals at the 24-year (a, c) and 16year (b, d) dominant periods, for the spring precipitation at the 16-year dominant period (e), for the autumn precipitation at the 23-year dominant period (f), and for the winter precipitation at the 17-year dominant period (g). 
Table 5. Statistical results of the multi-scale time-frequency characteristics from the EEMD of summer precipitation signals.

\begin{tabular}{ccrrrrr}
\hline $\begin{array}{c}\text { Precipitation } \\
\text { signals }\end{array}$ & $\begin{array}{c}\text { EEMD } \\
\text { components }\end{array}$ & $\begin{array}{r}\text { Average } \\
\text { frequency } \\
(1 / \text { year })\end{array}$ & $\begin{array}{r}\text { Average } \\
\text { period } \\
\text { (year) }\end{array}$ & $\begin{array}{r}\text { Average } \\
\text { amplitude } \\
(\mathrm{mm})\end{array}$ & $\begin{array}{r}\text { Variance } \\
\text { contribution } \\
(\%)\end{array}$ & $\begin{array}{r}\text { Correlation } \\
\text { coefficient with } \\
\text { original signal }\end{array}$ \\
\hline Ganyu summer \\
precipitation & IMF1 & 0.3287 & 3.0 & 177.8 & 49.6 & 0.73 \\
& IMF2 & 0.1689 & 5.9 & 94.3 & 13.9 & 0.45 \\
& IMF3 & 0.0865 & 11.6 & 122.1 & 27.6 & 0.39 \\
& R5 & 0.0566 & 17.7 & 71.1 & 7.3 & 0.08 \\
Dongtai & 0.2735 & 3.7 & 560.1 & 1.6 & 0.10 \\
summer & IMF1 & 0.3513 & 2.8 & 234.0 & 72.1 & 0.82 \\
precipitation & IMF2 & 0.1783 & 5.6 & 105.0 & 13.9 & 0.41 \\
& IMF4 & 0.0998 & 10.0 & 58.4 & 4.9 & 0.28 \\
& R5 & 0.0426 & 23.5 & 85.1 & 8.5 & 0.26 \\
Shanghai & IMF1 & 0.3332 & 3.0 & 562.2 & 0.6 & 0.15 \\
summer & IMF2 & 0.3332 & 3.0 & 176.1 & 52.5 & 0.72 \\
precipitation & IMF3 & 0.0736 & 13.6 & 44.5 & 4.2 & 0.43 \\
& IMF4 & 0.0175 & 57.1 & 96.0 & 9.5 & 0.17 \\
& & 0.2373 & 4.2 & 490.6 & 0.9 & 0.41 \\
& & & & & & 0.35 \\
\hline
\end{tabular}

Similarly, the future precipitation trends at the Ganyu and Shanghai stations were deduced and forecasted. Results showed that the annual and summer precipitation in the next 8-10 years, the autumn precipitation in the next 6 years and the winter precipitation in the next 7 years at the Ganyu station would probably be in the relatively low periods, because all their wavelet coefficients at the corresponding dominant periods in 2011 located at the end of each high-precipitation half-period. With respect to the Ganyu spring precipitation, it would still be in a relatively low period in the next 2 years and then revert to a relatively high period in the next 3 years, because the wavelet coefficient in 2011 located at the first year of one low-precipitation half-period. At the Shanghai station, all the annual and summer precipitation in the next $5-12$ years, the spring precipitation in the next 12 years and the winter precipitation in the next 8 years would probably be in the relatively low periods. With respect to the Shanghai autumn precipitation, it would still be in a relatively high period in the next 2 years and then revert to a relatively low period in the next 12 years. The above forecast showed an overall decreasing trend of precipitation in the next future years in the studied coastal region.

\section{Discussions}

\subsection{Improvement of multi-scale periodic characteristics revealing capabilities by combining continuous wavelet transform (CWT) and Hilbert-Huang transform (HHT) methods}

The previous studies (Zhu and Wang, 2001; Wei and Zhang, 2009; Zhu et al., 2011) have reported the significant decadal quasi periodic oscillation (QPO) of summer precipitation at about 30 years and interannual QPOs of summer precipitation at about 2 and 8 years in both the Huaihe River valley and the Yangtze River lower reach in China. The climate background is the corresponding decadal and interannual QPOs characteristics in the East Asian summer monsoon circulation (Chang et al., 2000). Among the three studied stations in the coastal region, the Ganyu station is located at the north part of Huaihe River Valley, the Shanghai station is located at the south part of the Yangtze River Lower Reach, and the Dongtai station is located at the crossing part of the two valleys. Based on the popular CWT method, the summer precipitation signals in the studied stations show significant broad-scale periodicities at approximate 9 years and 25 years, which match the approximate 8 - and 30-year scale QPO characteristics in the two valleys precipitation. However, the summer precipitation periodicity at fine scale in the studied stations, revealed by the CWT, shows very poor significances; this does not match the significant interannual QPO characteristic at about a 2-year scale in the two valleys precipitation. The main reason causing the poor performance of CWT method on revealing the fine-scale periodicity in the 

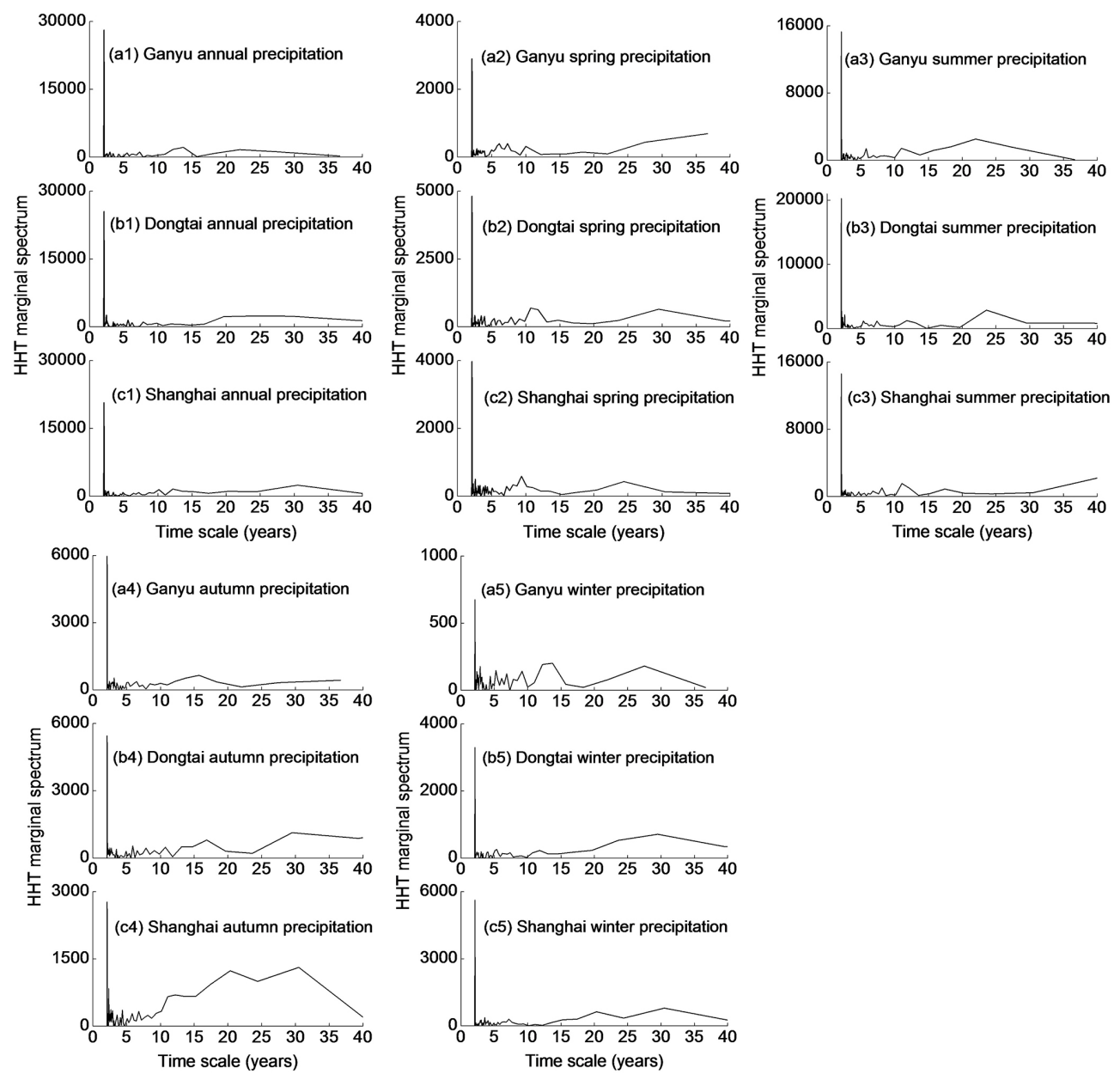

Figure 6. HHT marginal spectra of the annual (1) and seasonal (2-5) precipitation signals at the studied three stations.

coastal precipitation is the mode mixing problem in the CWT process, e.g., the precipitation $\mathrm{QPO}$ at a fine time scale is often nested in a broad time scale QPO in Fig. 3. In addition, the precipitation dynamic in the coastal region is often influenced by some unique climatic and environmental factors, such as the typhoon and the storm tide. These factors may lead some stochastic impacts on the periodic characteristics in the coastal precipitation and decrease the significance of fine-scale periodicities, which may aggravate the mode mixing in the CWT.

Since the improved HHT method, which is based on the ensemble empirical mode decomposition (EEMD) algorithm, has been popularly used in recent years in decomposing data into multi-scale IMF components with prominent advantage in eliminating the mode mixing drawback in the traditional Empirical Mode Decomposition (EMD), the following study tries to introduce the improved HHT method into eliminating the mode mixing problem in the CWT analysis of the studied precipitation signals multi-scale periodic characteristics.
For each summer precipitation signal, the statistical results of five decomposition components obtained from the EEMD are displayed in Table 5. The corresponding HHT marginal spectra based on EEMD are shown in Fig. 6a3, b3 and c3). In the EEMD process, an ensemble size of 100 is used, and the added white noise in each ensemble member has a standard deviation of 0.2. Among the five decomposition components of each summer precipitation signal, IMF1-IMF4 are intrinsic mode function components at multiple frequencies and $R 5$ is a trend component. For each summer precipitation signal, the fist decomposed IMF1, which denotes an average period at approximately 2 years, has the highest variance contribution ratios and the most significant correlation coefficients with the original data. For the corresponding HHT marginal spectrum of each summer precipitation signal, the most significant amplitude (or energy) accumulation occurs at the period of approximately 2 years. Further more, the EEMD-based HHT marginal spectra of the annual and the other seasonal precipitation signals (Fig. 6) show similar and significant fine-scale periodicities as the summer precipitation signal. Comparing the CWT method, the EEMD-based 

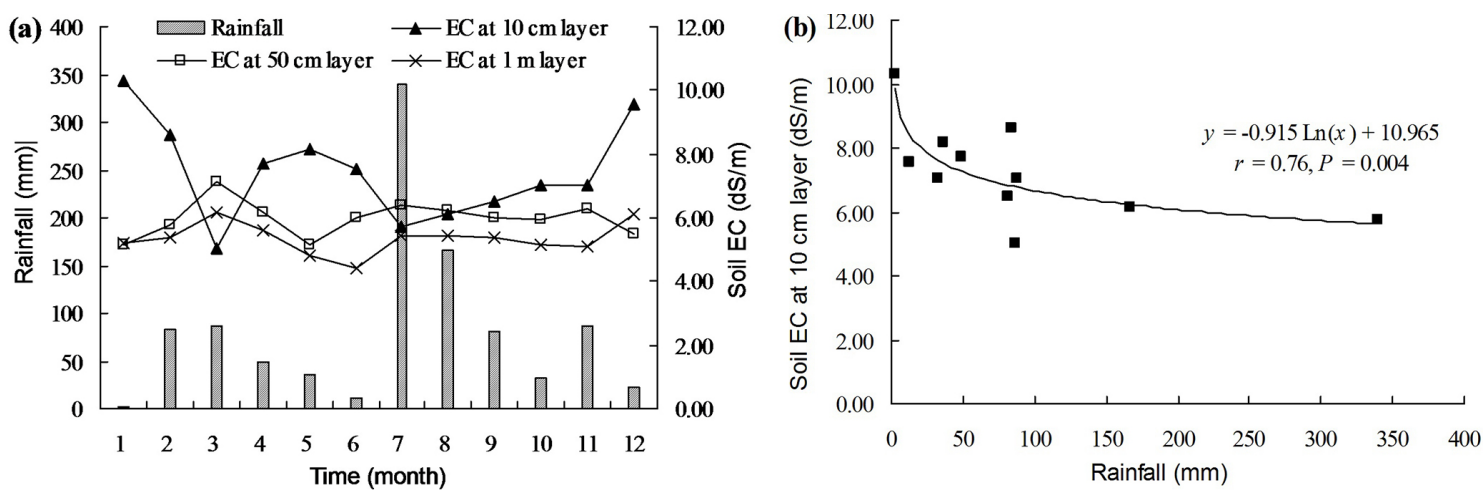

Figure 7. Monthly dynamics of the precipitation and soil EC of different layers in the new reclaimed farmland(a), and their correlation (b).

HHT method well improves the capabilities in eliminating the fine-scale mode mixing problem and in revealing the precipitation signals fine-scale periodic characteristics. As for the broad-scale periodicities analysis, the HHT results, that the annual and seasonal precipitation signals have approximate 9- and 25-year periodicities, match the CWT results. However, the significances in the broad-scale periodicities revealed by the HHT are slightly lower than that revealed by the CWT.

The above discussion proves that it is reasonable to accurately analyze the precipitation signals multi-scale periodicities by combining the CWT and HHT methods, i.e., using the EEMD-based HHT method to eliminate the fine-scale mode mixing drawbacks in the CWT and to improve the signal's multi-scale periodic characteristics. In view of this, the precipitation trend forecast based on the CWT should not ignore the precipitation signals fine-scale periodicities. In the case study, the three stations annual and seasonal precipitation trends at fine scales can be forecasted by deducing the future fluctuating of the wavelet transform coefficient curves at the corresponding periods of 2-3 years. Results show an overall decreasing trend of the precipitation in the next future 1-2 years in the studied stations, because all the finescale wavelet coefficients in 2011 locate at the end of each high-precipitation half period.

\subsection{Applying research results of precipitation multi-scale time-frequency characteristics to soil hydrological process study}

Before evaluating the impacts of coastal-region multi-scale precipitation trends on the soil hydrological process, the relationship between the precipitation dynamics and soil and groundwater salinization dynamics needs to be quantitatively analyzed first, which is shown in the following study by taking the relatively short monitoring data analysis in a newly cultivated farmland at the typical reclamation area Dongtai as an example.

The comparison results between the dynamics of monthly precipitation and monthly average soil electric conductiv- ity (EC), standing for soil salinity, at different soil layers are shown in Fig. 7a. Results show that the surface soil EC $(10 \mathrm{~cm}$ layer $)$ decreases significantly with the precipitation increase and increases with the precipitation decrease, with a significant correlation coefficient of 0.76 under the 0.01 confidence level $(P=0.004)$ by the logarithmic function fitting (Fig. 7b). On the contrary, see Fig. 7a, the 50 and $100 \mathrm{~cm}$ layers soil EC dynamics are in keeping with the precipitation dynamics. The positive correlation coefficient of 0.63 between the $50 \mathrm{~cm}$ layer soil EC and precipitation is significant under the 0.05 confidence level $(P=0.029)$ by the logarithmic function fitting, while the positive correlation coefficient of 0.44 between the $100 \mathrm{~cm}$ layer soil EC and precipitation is not significant under the 0.05 confidence level $(P=0.173)$ by the logarithmic function fitting. It seems that the soil salt is leached from the surface part to lower part when the precipitation increases. Further analysis shows that in average every $10 \mathrm{~mm}$ monthly precipitation increase in the monitoring site causes correspondingly $0.1-0.2 \mathrm{dS} \mathrm{m}^{-1}$ decrease of the surface soil EC (Fig. 7b).

Because of the shallow groundwater table, usually changing from 80 to $150 \mathrm{~cm}$ layer over the whole year at the studied coastal reclamation region, the groundwater salinity dynamics has very close relationship with the precipitation change. The daily precipitation and groundwater EC dynamics based on the original monitoring data covering 1 whole year are shown in Fig. 8a. Results show that the groundwater EC usually increases significantly when the precipitation increases and leaches soil salt downwards. While, when the precipitation is low and evaporation is high, the salt in groundwater moves upwards into soil and the groundwater EC decreases. Based on the daily precipitation and groundwater EC data series, the cross wavelet power spectrum from cross wavelet transform (XWT) and the corresponding wavelet transform coherence (WTC) results are shown in Fig. 8b and c, respectively. Since the $r(1)$ of daily groundwater EC and precipitation series are 0.98 and 0.30 , respectively, the red noise test in XWT is chosen. Prominent resonant periods of the two signals around the 5-, 15-, 25- and 70-day bands stand out 
(a)

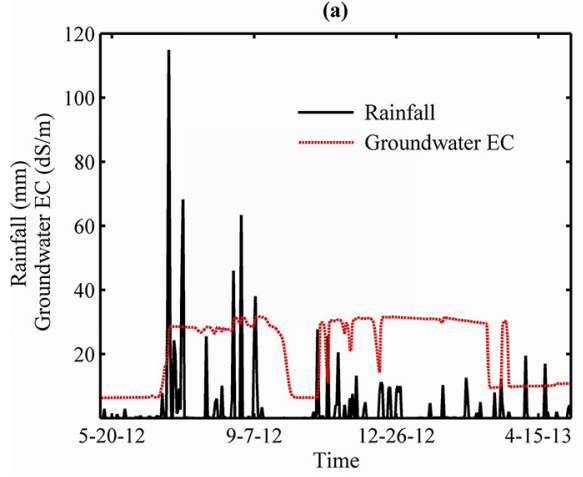

(b)

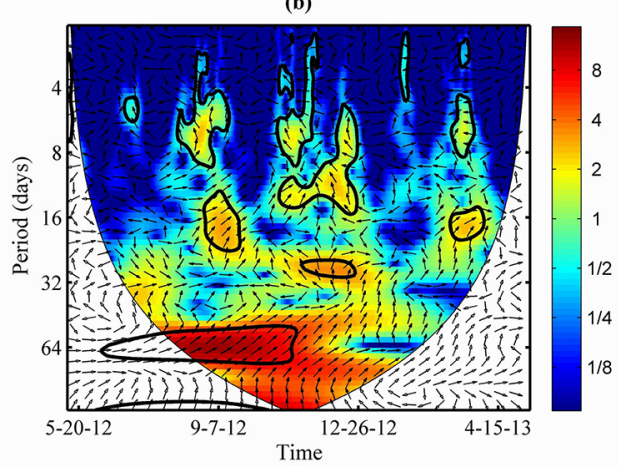

(c)

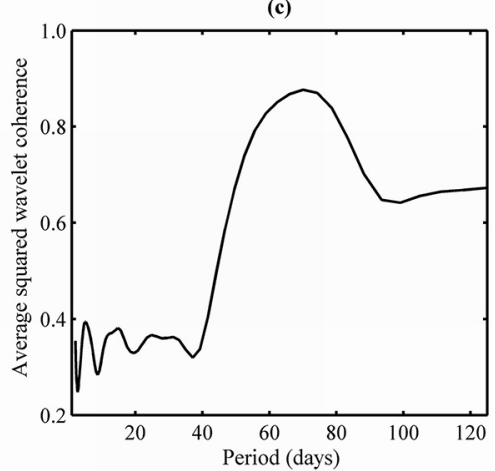

Figure 8. Original precipitation and groundwater EC data series (a), and their cross wavelet transform (b) and the corresponding average squared wavelet coherence coefficients (c). The thick black contour in (b) denotes the 0.05 significance level against the red noise test, the cone of influence where the edge effects might distort the picture is shown as a lighter shade, and the relative phase relationship is shown as the arrows (with in-phase pointing right, anti-phase pointing left).

as being significant at the 0.05 significance level. The average squared wavelet coherence coefficient between the two signals around the 70-day band is the highest and equals to 0.88 , which proves the most significant oscillation coherence between the two series at the periods around 70-day band. In view of this, the XWT phase angles within the 0.05 significant regions around the 70-day band are reasonable to be calculated. The mean phase $-34.1 \pm 5.3^{\circ}$ (where \pm designates the circular standard deviation) at the periods around 70-day band is in-phase, which indicates about 5-7-day lag of the impact of precipitation dynamics on the groundwater EC dynamics.

The above discussion indicates that the precipitation increase at the coastal reclamation area can be very helpful for the surface soil salt leaching, while may increase the salt accumulation in the deeper soil profile and groundwater, which asks for reasonable drainage measures especially in rainy seasons to prevent the coastal groundwater salinization. The revealed future decreasing trend of precipitation, especially in spring and summer, in the studied coastal region has negative impact on the surface soil salt leaching, thus may aggravate the salinization in the salt-affected coastal land and probably lead a new secondary salinization process in the newly desalted and cultivated land in future years. This suggests reasonable salt leaching and evaporation suppression measures to prevent soil salinization, especially the root-zone salinization, in future years.

It should be noted that the precipitation trend forecast based on CWT and HHT in this study is qualitative. Thus, the further quantitative evaluation of precipitation trend and its impacts on soil and groundwater salinization in future research may need more advanced mathematical models and algorithms, such as discrete wavelet transform and neurofuzzy models (Yang et al. 2013), and have to pay more attention to the impacts of stochastic factors. In addition, because the soil and groundwater salinities monitoring site in this study is located at a newly cultivated farmland, the longer time series of soil and groundwater salinities monitoring data need to be collected in the future research for the improvement of quantitative analysis between the precipitation and salinization dynamics.

\section{Conclusions}

This study conducts a detailed analysis of multi-scale periodic characteristics involved in the annual and seasonal precipitation signals at different meteorological stations along the coastal reclamation region by using and comparing two types of popular continuous wavelet transforms (CWTs) and their wavelet power spectrums. Furthermore the future annual and seasonal precipitation trends in the studied coastal stations are deduced and forecasted by selecting a suitable wavelet to reveal the dominant precipitation periods. The critical fine-scale mode mixing problem in the CWT process is discussed and innovatively improved by combining the EEMD-based Hilbert-Huang transform (HHT) method. In addition, by analyzing the quantitative relationship between the precipitation dynamics and soil and groundwater salinities dynamics, some novel attempts are made to evaluate the impact of the revealed precipitation trend on the future soil hydrological process in a newly cultivated coastal farmland. Some interesting conclusions can be drawn as follows.

1. By combining the CWT and the corresponding wavelet power spectrum test, the multi-scale periodic characteristics, mainly the broad-scale periodicities, of annual and seasonal precipitation signals in the studied coastal reclamation region are revealed. Comparing the performances of two popular CWTs, the Morlet wavelet transform is proved more suitable than the Mexican hat in the studied area, because the Morlet shows more advantage in capturing the oscillatory behaviors and revealing the local feature of coastal precipitation periodicity, es- 
pecially in increasing the confidence level of wavelet power spectrum test.

2. Comparing the traditional method of judging the precipitation trend by the climate tendency rate, which shows relatively poor significances, the CWT-based forecast approach by deducing the future wavelet coefficients dynamics at the dominant precipitation period with the highest significance level is proved more reasonable. By means of this approach, a general decreasing trend in the coastal annual and seasonal precipitation in future years is demonstrated.

3. Although the superiorities of CWT method in revealing the precipitation signals broad-scale periodicities and forecasting the precipitation trend are proved, the critical fine-scale mode mixing problem in CWT causes the poor significances of fine-scale periodicities, which cannot well match the previous studies on the whole valleys precipitation periodicities and on the climate backgrounds. Thus, the EEMD-based HHT method is innovatively introduced into the effective elimination of fine-scale mode mixing drawback in CWT. It is demonstrated reasonable to accurately analyze the precipitation signals multi-scale periodicities by combining the CWT and HHT methods.

4. The demonstrated prominent correlations between the precipitation dynamics and soil and groundwater salinities dynamics indicate that the precipitation increase can effectively leach the surface soil salt downwards, but may aggravate the salt accumulation in the deeper soil layers and groundwater, which asks for reasonable drainage measures in rainy seasons to prevent the possible groundwater salinization. By innovatively using the cross wavelet transform (XWT) and wavelet transform coherence (WTC) approaches, the significant coherence around the 70-day resonant period between the precipitation dynamics and groundwater salinity dynamics is revealed, which indicates the approximate 5-7day lag of the impact of precipitation dynamics on the groundwater salinity. Thus, the revealed future decreasing trend of precipitation, especially in spring and summer, may aggravate the soil salinization at the studied coastal reclamation region, which asks for reasonable salt leaching and evaporation suppression measures to prevent the future soil secondary salinization process. In addition, some ideas about the further improvements of quantitative evaluation of precipitation trend and its impacts on the soil hydrological process and of longer monitoring data collection in the new cultivated land are proposed.
Acknowledgements. This study is financially supported by the Natural Science Foundation of China (grant nos. 41101518 and 41171181), and the University-Industry Cooperative Innovation Project of Jiangsu Province, China (no. BY2013062). Cordial thanks should be extended to the editors and the anonymous reviewers. The Cross Wavelet Transform software package was provided by A. Grinsted, J. C. Moore and S. Jevrejeva, and is available at http://noc.ac.uk/using-science/crosswavelet-wavelet-coherence.

Edited by: L. Ferraris

Reviewed by: two anonymous referees

\section{References}

Allen, M. R. and Smith, L. A.: Monte Carlo SSA: Detecting irregular oscillations in the presence of coloured noise, J. Clim., 9, 3373-3404, 1996.

Chang, C. P., Zhang, Y. S., and Li, T.: Interannual and interdecadal variations of the East Asian summer monsoon and tropical pacific SSTs, I-II, J. Clim., 13, 4310-4340, 2000.

Coulibaly, P. and Burn, H. D.: Wavelet analysis of variability in annual Canadian streamflows, Water Resour. Res., 40, W03105, doi:10.1029/2003WR002667, 2004.

Daubechies, I.: Ten Lectures on wavelets, CBMS-NSF Regional Conference Series in Applied Mathematics, SIAM, 61, 194-202, 1994.

Farge, M.: Wavelet transforms and their applications to turbulence, Ann. Rev. Fluid Mech., 24, 395-457, 1992.

Foufoula-Georgiou, E. and Kumar, P.: Wavelets in Geophysics, Academic Press, New York, USA, 373 pp., 1995.

Ge, Z.: Significance tests for the wavelet power and the wavelet power spectrum, Ann. Geophys., 25, 2259-2269, 2007, http://www.ann-geophys.net/25/2259/2007/.

Gong, Z. Q., Zou, M. W., Gao, X. Q., and Dong, W. J.: On the difference between empirical mode decomposistion and wavelet decomposition in the nonlinear time series, Acta Physica Sinica, 54, 3947-3957, 2005 (in Chinese).

Grinsted, A., Moore, J. C., and Jevrejeva, S.: Application of the cross wavelet transform and wavelet coherence to geophysical time series, Nonlin. Processes Geophys., 11, 561-566, doi:10.5194/npg-11-561-2004, 2004.

Grossmann, A. and Morlet, J.: Decomposition of hardy functions into square integrable wavelets of constant shape, SIAM J. Math. Anal., 15, 723-736, 1984.

Gurley, K., Kijewski, T., and Kareem, A.: First and higher order correlation detection using wavelet transforms, J. Eng. Mech., 129, 188-201, 2003.

Huang, N. E. and Wu, Z. H.: A review on Hilbert-Huang transform: Method and its applications to geophysical studies, Rev. Geophys., 46, RG2006, doi:10.1029/2007RG000228, 2008.

Huang, N. E., Shen, Z., Long, R. S., Wu, M. C., Shih, E. H., Zheng, Q., Tung, C. C., and Liu, H. H.: The empirical mode decomposition method and the Hilbert spectrum for non-stationary time series analysis, Proc. Roy. Soc. London A, 454, 903-995, 1998.

Huang, N. E., Shen, Z., and Long, R. S.: A new view of nonlinear water waves - the Hilbert spectrum, Ann. Rev. Fluid Mech., 31, 417-457, 1999 . 
Jevrejeva, S., Moore, J. C., and Grinsted, A.: Influence of the Arctic Oscillation and El Nino-Southern Oscillation (ENSO) on ice conditions in the Baltic Sea: The wavelet approach, J. Geophys. Res., 108, 4677, doi:10.1029/2003JD003417, 2003.

Labat, D., Ababou, R., and Mangin, A.: Rainfall-runoff relations for karstic springs - Part II: Continuous wavelet and discrete orthogonal multiresolution analyses, J. Hydrol., 238, 149-178, 2000.

Labat, D., Ronchail, J., and Guyot, J. L.: Recent advances in wavelet analyses - Part 2: Amazon, Parana, Orinoco and Congo discharges time scale variability, J. Hydrol., 314, 289-311, 2005.

Liu, P. C.: Wavelet spectrum analysis and ocean wind waves, in: Wavelets in Geophysics, edited by: Foufoula-Georgiou, E. and Kumar, P., Academic Press, New York, USA, 151-166, 1994.

Liu, D. L., Liu, X. Z., Li, B. C., Zhao, S. W., and Li, X. G.: Multiple time scale analysis of river runoff using wavelet transform for Dagujia River Basin, Yantai, China, Chin. Geogra. Sci., 19, 158167, 2009.

Mallat, S.: A theory for multiresolution signal decomposition: the wavelet representation, IEEE T. Pattern. Anal., 11, 674-693, 1989.

Mandelbrot, B. B. and Wallis, J. R.: Noah, Joseph and Operational Hydrology, Water Resour. Res., 4, 909-918, 1968.

Meng, E. J. and Tang, B. P.: Jiangsu seabeach resources and the development strategy, Southeast University Process, Nanjing, China, 180-210, 2010 (in Chinese).

Nener, B. D., Ridsdill-Smith, T. A., and Zeisse, C.: Wavelet analysis of low altitude infrared transmission in the coastal environment, Infrared Phys. Tech., 40, 399-409, 1999.

Roth, P. R.: Effective measurements using digital signal analysis (correlation, transfer and coherence functions in measurements, using digital signal analysis), IEEE Spectrum, 8, 62-70, 1971.

Sadowskey, J.: Investigation of signal characteristics using the continuous wavelet transform., J. Hopkins APL Tech. D., 17, 258269, 1996.

Shark, L. K. and Yu, C.: Design of matched wavelet based on generalized Mexican-Hat function, Signal Process., 86, 1451-1469, 2006.

Torrence, C. and Compo, G. P.: A practical guide to wavelet analysis, B. Am. Meteorol. Soc., 79, 61-78, 1998.

Torrence, C. and Webster, P. J.: Interdecadal changes in the EnsoMonsoon System, J. Clim., 12, 2679-2690, 1999.

Walker, J. S.: Fourier analysis and wavelet analysis, Notices Am. Math. Soc., 44, 658-670, 1997.

Wang, X. Y. and Ke, X. K.: Grain size characteristics of the extant tidal flat sediments along the Jiangsu coast, China, Sediment Geol., 112, 105-122, 1997.
Wang, Y., Cao, M. K., Tao, B., and Li, K. R.: The characteristics of spatio-temporal patterns in precipitation in China under the background of global climate change, Geogr. Res., 25, 1031-1041, 2006 (in Chinese).

Wei, F. Y. and Zhang, T.: Oscillation characteristics of summer precipitation in the Huaihe River valley and relevant climate background, Sci. China Ser. D, 39, 1360-1374, 2009 (in Chinese).

Wu, Z. H. and Huang, N. E.: Ensemble empirical mode decomposition: A noise-assisted data analysis method, Adv. Adapt. Data Anal., 1, 1-41, 2009.

Xu, Y. Q., Li, S. C., and Cai, Y. L.: Wavelet-based characteristics of rainfall behaviors in the Hebei Plain, China, Sci. China Ser. D, 34, 1176-1183, 2004 (in Chinese).

Yang, R. W., Cao, J., Huang, W., and Nian, A. B.: Cross wavelet analysis of the relationship between total solar irradiance and sunspot number, Chinese Sci. Bull., 54, 871-875, 2009.

Yang, J.-S., Yu, S.-P., and Liu, G.-M.: Multi-step-ahead predictor design for effective long-term forecast of hydrological signals using a novel wavelet neural network hybrid model, Hydrol. Earth Syst. Sci., 17, 4981-4993, doi:10.5194/hess-17-49812013, 2013.

Yu, S. P., Yang, J. S., and Liu, G. M.: A novel discussion on two long-term forecast mechanisms for hydro-meteorological signals using hybrid wavelet-NN model, J. Hydrol., 497, 189-197, 2013.

Yu, S. P., Yang, J. S., and Liu, G. M.: Impact assessment of Three Gorges Dam's impoundment on river dynamics in the north branch of Yangtze River estuary, China, Environ. Earth Sci., 72, 499-509, 2014.

Zar, J. H.: Biostatistical analysis, Prentice Hall, New Jersey, USA, 800-920, 1999.

Zhang, Q., Xu, C. Y., and Chen, Y. D.: Wavelet-based characterization of water level behaviors in the Pearl River estuary, China. Stoch. Env. Res. Risk A, 24, 81-92, 2010.

Zhao, X. F., Yang, J. S., and Yao, R. J.: Relationship between soil salt dynamics and factors of water balance in the typical coastal area of Northern Jiangsu Province, T. Chinese Soc. Agr. Eng., 26, 52-57, 2010 (in Chinese).

Zhu, J. H. and Wang, S. W.: 80a-Oscillation of summer rainfall over the East Part of China and East-Asian Summer Monsoon, Adv. Atmos. Sci., 18, 1043-1051, 2001.

Zhu, Y. L., Wang, H. J., Zhou, W., and Ma, J. H.: Recent changes in the summer precipitation pattern in East China and the background circulation, Clim. Dyn., 36, 1463-1473, 2011. 